\title{
Rapid Ag Nanofiber Formation via Pt Nanoparticle- Assisted H2-Free Reduction of Ag+-Containing Polymers
}

Xu Zhao ( $\nabla$ zhao@gipc.akita-u.ac.jp )

Akita University: Akita Daigaku https://orcid.org/0000-0002-5803-4057

\section{Yukiko Kawamura}

Akita University: Akita Daigaku

Mikio Muraoka

Akita University: Akita Daigaku

\section{Nano Express}

Keywords: Ag nanofibers, aspect ratio, percolation, transparent conductive films

Posted Date: September 4th, 2020

DOl: https://doi.org/10.21203/rs.3.rs-70452/v1

License: (c) (i) This work is licensed under a Creative Commons Attribution 4.0 International License.

Read Full License 


\section{Abstract}

One-dimensional Ag nanostructure-based networks have garnered significant attention as next-generation transparent conductive materials. Compared to Ag nanowires, Ag nanofibers (NFs) with higher aspect ratios decrease the number density required for percolation; hence, they form qualitatively superior transparent conductive films. This study reports a novel method for rapid fabricating Ag NFs via the Pt nanoparticle-assisted $\mathrm{H}_{2}$-free reduction of solid-state $\mathrm{AgNO}_{3}$. Our results firstly indicated that polymers can be a source of reducing gases in the presence of Pt nanoparticles; Ag NFs with aspect ratios above $10^{5}$ herein were obtained by heating $\mathrm{AgNO}_{3}$-containing polymer NFs in an open-air environment. The obtained Ag NF networks were highly conductive and transparent. Moreover, the mechanism of Ag NF formation was investigated. We demonstrate that the proposed method exhibits a high potential for producing high yields of Ag NFs in a simple and rapid manner.

\section{Introduction}

Transparent conductive films are widely used as transparent electrodes in liquid crystal displays, solar cells, smart windows, and touch screens [1-6], transparent film heaters [7-11], and electromagnetic wave shielding materials [12-14]. The latest transparent conductive material, indium tin oxide (ITO), has outstanding conductivity and transparency in the visible region [15]. However, with the increasing demand for flexible conductive materials in recent years, the lack of flexibility of ITO and scarcity of In have prompted research into viable alternatives. Numerous candidates such as carbon nanotubes $[1,7,16]$, graphite $[8,17,18]$, conducting polymers $[19,20]$, and metallic nanowires (NWs) [3-5,9-11] have been extensively studied. Particularly, Ag NW networks $[3,4,9]$ appear to be the promising alternatives. In addition to the excellent conductivity, stretchability, and flexibility derived from the metallic properties of $\mathrm{Ag}$, a wire diameter smaller than the visible light wavelengths ensures high transparency of the network. Compared to ITO, Ag NW networks benefit from a wider wavelength range with exceedingly high transparency [21]. This can be applied to photovoltaic systems for improving the conversion efficiency of solar cells.

Currently, the polyol approach $[22,23]$ is the most promising route for synthesizing Ag NWs. The Ag NWs synthesized by this solution-based process can easily be dispersed to form a network. However, the contact points between the NWs strongly influence the properties of the networks. The high contact resistance greatly increases the sheet resistance, while the weak bond worsens the mechanical properties when the network is deformed. Previous studies have indicated that longer NWs could yield qualitatively better transparent conductive films, because doubling the length of NWs decreases the number density required for percolation by a factor of four [24]. Nevertheless, existing synthesis methods have limited the length of Ag NWs to several tens of micrometers and aspect ratios to $10^{2}-10^{3}$; hence, the issues caused by the contact points remain a challenge.

Compared to Ag NWs, Ag nanofibers (NFs) are approximately the same size in diameter, but they are much longer (usually several tens of millimeters) and with higher aspect ratios that can reach $10^{5}-10^{6}$. 
However, there are few reports on the synthesis of Ag NFs. Although $\mathrm{Ag}^{+}$-containing precursor NFs can be mass-produced through electrospinning [2] and blow-spinning [25], the challenges faced in this synthesis include the reduction of $\mathrm{Ag}^{+}$to form continuous $\mathrm{Ag} \mathrm{NFs}$ and the decomposition of the residual insulating polymers originating from the precursor solution. Recently, Lin et al. reported a method for reducing silver nitrate $\left(\mathrm{AgNO}_{3}\right) \mathrm{NFs}$ by UV irradiation [6]. A large-scale Ag NF network was obtained after $3 \mathrm{~h}$ of UV irradiation to reduce $\mathrm{Ag}^{+}$. Nevertheless, the reduction process was relatively long and the decomposition of residual polymers remained an issue.

This study reports a simple method for the fabrication of Ag NFs. Our finding indicates that polymers can be a source of reducing gases in the presence of Pt nanoparticles; we obtained Ag NFs with high aspect ratios by heating $\mathrm{AgNO}_{3}$-containing polymer NFs. The resultant $\mathrm{Ag} \mathrm{NF}$ networks were highly conductive and transparent. This proposed method has high potential for producing high yields of Ag NFs in a simple and rapid manner.

\section{Experimental}

The experimental procedure for the fabrication of the Ag NF networks is illustrated in Fig. 1. Pt nanoparticles were deposited on an $18 \times 18 \mathrm{~mm}^{2}$ micro cover glass substrate, of thickness $120-170 \mu \mathrm{m}$, using a magnetron sputtering system at $23^{\circ} \mathrm{C}$ (Fig. 1a). The deposition pressure and rate were $1.5 \mathrm{~Pa}$ and $2.5 \AA / s$ at $25 \mathrm{~mA}$, respectively. The deposition time was $4 \mathrm{~s}$, after which the thickness of the deposited Pt was $1 \mathrm{~nm}$. Notably, this thickness did not result in a continuous Pt film, but discontinuous islands (nanoparticles). This phenomenon is known as the initial stage of thin metal film growth [26-28]. These Pt nanoparticles are crucial in the fabrication of Ag NFs, as discussed in detail later. After the deposition of the Pt nanoparticles, an electrospun $\mathrm{AgNO}_{3}$ /polyvinyl alcohol (PVA)/polyvinyl pyrrolidone (PVP)-mixed $\mathrm{NF}$ network was deposited onto the substrate by applying $20 \mathrm{kV}$ voltage across the $\mathrm{AgNO}_{3} / \mathrm{PVA} / \mathrm{PVP}$ aqueous solution for $5 \mathrm{~min}$, at a collection distance of $15 \mathrm{~cm}$ (Fig. 1b). A syringe, with a needle of 0.41 $\mathrm{mm}$ inner diameter, was connected to a micropump. The flow rate of the micropump was set to 0.05 $\mathrm{mL} / \mathrm{h}$. The pumped solution was composed of $\mathrm{AgNO}_{3}, \mathrm{PVA}, \mathrm{PVP}$, and deionized water in a weight ratio of 10:8.5:4:100 in wt.\%, respectively. The viscosity of the solution was $277 \mathrm{mPa} \cdot \mathrm{s}$. The molecular weights of PVA and PVP are $6.6 \times 10^{4} \mathrm{~g} / \mathrm{mol}$ and $1.332 \times 10^{8} \mathrm{~g} / \mathrm{mol}$, respectively. PVA is a common polymer material used for electrospinning, while PVP is used as a molecular capping agent. Finally, the specimens were heated in air at $250{ }^{\circ} \mathrm{C}$ for 30 min to reduce $\mathrm{AgNO}_{3}$ to $\mathrm{Ag}$ in the presence of Pt nanoparticles (Fig. 1c). The products were measured using the four-probe method and analyzed by field-emission scanning electron microscopy (FE-SEM: SU-70, HITACHI Co., Ltd.), high-angle annular dark field scanning transmission electron microscopy (HAADF-STEM: Talos F200X, FEl Co., Ltd.), energy dispersive X-ray (EDX), and Raman spectrometry (RAMANtouch, Nanophoton Co., Ltd.).

\section{Results And Discussion}


Figure 2a shows the states of the specimens during the experiment. Each specimen is marked with a dashed line. The illustrations from left to right are the as-prepared glass substrate, the glass after Pt sputtering, after electrospinning of the NF network, after heating (the yellow portions are Au electrodes in size of $18 \times 1.5 \mathrm{~mm}^{2}$ used for resistance measurement), and a 15-nm-thick Ag film deposited on a glass substrate for reference. After heating, the specimen displays high transparency in the visible region (Fig. 2b). The long NF-percolated network is clearly illustrated in the magnified view of SEM micrograph (Fig. $2 b$ ). The area fraction of the network, measured by applying thresholds to the SEM micrograph using an image analysis software (WinROOF2015, MITANI Corporation), is approximately 47\%. The HAADF-STEM analysis (Fig. 2c) demonstrates that the NFs are several tens of nanometers in diameter and have a polycrystalline microstructure. The length of the electrospun NFs could span the entire substrate $(18 \times 18$ $\mathrm{mm}^{2}$ ) or even longer; hence, the aspect ratio of the present NFs reached an order of $10^{5}$ or even larger. The EDX analysis results (Figs. $2 \mathrm{~d}$ to $2 \mathrm{~g}$ ) indicate that the network is composed of Ag NFs, with no Crelated distribution in the NFs. Moreover, Pt was not detected, probably because of its small amount. The detected $\mathrm{Si}, \mathrm{O}, \mathrm{Na}$, Al, and $\mathrm{K}$ elements (Fig. $2 \mathrm{~g}$ ) originated from the glass substrate, and thus can be ignored. The measured current-voltage curves (Fig. 2h) demonstrate that the formed Ag NF networks have metallic properties, and their sheet resistances are as low as several tens of $\Omega / \square$, which is comparable to that of commercially available ITOs.

As a result, the role of Pt nanoparticles and the importance of a heating in air, instead of under vacuum have been questioned. Therefore, these aspects are discussed in the following paragraphs.

The initial purpose of Pt nanoparticle deposition was to improve the electrospinning process, so that more $\mathrm{AgNO}_{3} / \mathrm{PVA} / \mathrm{PVP} \mathrm{NFs}$ could be deposited on the insulated glass substrate. Interestingly, when we heated the $\mathrm{AgNO}_{3} / \mathrm{PVA} / \mathrm{PVP} \mathrm{NFs}$ with the Pt nanoparticles at $250^{\circ} \mathrm{C}$, we obtained Ag NFs. The EDX analysis results (Figs. $2 \mathrm{~d}$ to $2 \mathrm{~g}$ ) and measured sheet resistances (Fig. $2 \mathrm{~h}$ ) strongly support this novel finding. It is highly improbable that $\mathrm{Ag}$ was produced by the thermal decomposition of $\mathrm{AgNO}_{3}$ after heating at $250{ }^{\circ} \mathrm{C}$ because the decomposition occurs at temperatures above $500{ }^{\circ} \mathrm{C}$ [29]. Therefore, it is more likely that the $\mathrm{Ag}$ was produced from the hydrogen reduction of $\mathrm{AgNO}_{3}$. Moreover, the hydrogen gas most likely came from PVA and PVP used in the present experiments. However, till date, there have been no reports that hydrogen gas can be directly generated from the thermal decomposition of PVA or PVP. Most reports have indicated that the main decomposition product of PVA at approximately $200{ }^{\circ} \mathrm{C}$ is $\mathrm{H}_{2} \mathrm{O}$ [30-33]. We postulate that Pt nanoparticles are the decisive factor for the reduction process. Pt has undergone plenty of research and is well-known as a catalyst for chemical reactions.

The above discussion is summarized by Eqs. (1) and (2) given below.

$$
\left[\mathrm{CH}_{2} \mathrm{CHOH}\right]_{n} \underset{\text { in air }}{\stackrel{\mathrm{Pt}}{\longrightarrow}} \mathrm{CO}_{2}+\mathrm{H}_{2}+\mathrm{H}_{2} \mathrm{O}
$$

and

$$
\mathrm{H}_{2}+\mathrm{Ag}^{+} \rightarrow \mathrm{Ag}+\mathrm{H}^{+}
$$


The main components of PVA $\left(\left[\mathrm{CH}_{2} \mathrm{CHOH}\right]_{n}\right)$ and PVP $\left(\left[\mathrm{C}_{6} \mathrm{H}_{9} \mathrm{NO}\right]_{n}\right)$ are similar, and PVA accounts for the majority of the electrospinning solution; therefore, we focus on PVA in the following discussion. The reactions shown in Eqs. (1) and (2) were proposed based on our speculation because it is significantly challenging to prove that PVA produces hydrogen gas via thermal decomposition in the presence of $\mathrm{Pt}$ nanoparticles. However, according to our experimental results and other comprehensive considerations, these reactions seem most likely to have occurred. To verify the catalytic effect of the Pt nanoparticles, other metal nanoparticles were also deposited (similar to the process shown in Fig. 1a) and the experiments were repeated. As shown in Table 1, Ag and Au nanoparticles were deposited onto the glass substrates. Their thicknesses were restricted to $1 \mathrm{~nm}$, which is similar to that of Pt nanoparticles. Glass substrates without any nanoparticle deposition were also prepared for drawing comparison. To ensure the reproducibility of the experimental results, at least four test pieces were prepared for each type of metal nanoparticle. These test pieces were then subjected to electrospinning (Fig. 1b) and heating (Fig. 1c) under the same conditions as those used for Pt nanoparticles. Comparing the sheet resistances before and after heating demonstrates that only the sheet resistances of the test pieces with Pt nanoparticles were greatly reduced from insulated to several tens to hundreds of $\Omega / \square$. This implies that the component changed from $\mathrm{AgNO}_{3}$ to $\mathrm{Ag}$. Therefore, we conclude that Pt nanoparticles play a critical role in the successful fabrication of Ag NFs. Owing to the existence of Pt nanoparticles, the insulating polymer materials (PVA and PVP) were not only thermally decomposed, but effectively produced a gas that could reduce $\mathrm{AgNO}_{3}$.

Table 1 Sheet resistance variations of the test pieces with different metal nanoparticles

\begin{tabular}{|llll|}
\hline Nanoparticles & Heating conditions & \multicolumn{2}{l|}{ Sheet resistances of the test pieces $(\Omega / \square)$} \\
\cline { 3 - 4 } & & Before heating & After heating \\
\hline $\mathrm{Pt}$ & $250^{\circ} \mathrm{C}, 30 \mathrm{~min}$ & Insulated & Several tens to hundreds \\
\hline $\mathrm{Ag}$ & $250^{\circ} \mathrm{C}, 30 \mathrm{~min}$ & Insulated & Insulated \\
\hline $\mathrm{Au}$ & $250^{\circ} \mathrm{C}, 30 \mathrm{~min}$ & Insulated & Insulated \\
\hline None & $250^{\circ} \mathrm{C}, 30 \mathrm{~min}$ & Insulated & Insulated \\
\hline
\end{tabular}

Reduction of the metallic ions using gases is usually carried out under vacuum. Therefore, the size of the specimen is limited by the vacuum chamber, and a significant amount of time is spent creating the vacuum. Fortunately, our method does not require a vacuum because we found that an open-air environment is more suitable for fabricating highly conductive Ag NFs. For example, Fig. 3a shows a specimen (prepared by the same processes shown in Figs. 1a and 1b) after heating under vacuum (using a flow rate of $200 \mathrm{sccm}$ Ar gas and pressure of $130 \mathrm{~Pa}$, at $250{ }^{\circ} \mathrm{C}$ for $30 \mathrm{~min}$ ). Unlike the specimens heated in air, the pieces heated under vacuum were translucent and light brown in color. Remarkably, their sheet resistances are as high as several thousands of $\Omega / \square$, which is one to two orders of magnitude greater than those heated in air. The EDX analysis results (Figs. $3 \mathrm{~b}$ to $3 \mathrm{e}$ ) indicate that a significant 
amount of $\mathrm{C}$ is present in the NFs, while the detected $\mathrm{Si}, \mathrm{O}, \mathrm{Na}$, and $\mathrm{Al}$ elements (Fig. 3e) came from the glass substrate, and thus were ignored. Raman spectroscopic analysis (Fig. 3f) demonstrates that these carbons have an amorphous structure. Two characteristic peaks of Raman shifts around 1325 and 1583 $\mathrm{cm}^{-1}$ were detected, which is consistent with the peaks reported elsewhere [6]. Furthermore, as shown in Fig. 3f, an increase in the baseline of the Raman shift owing to the fluorescence was detected, which implies a high possibility of residual organics (polymers). Therefore, the test pieces heated under vacuum showed extra-large sheet resistances.

Figure $3 \mathrm{~g}$ displays the histograms of the NF diameter after heating in air and under vacuum. The diameters were measured using the measuring function of SEM. Under each heating condition, more than $40 \mathrm{NFs}$ were randomly selected for the SEM observations (at 5000x magnification) and subsequent measurements. Compared to those heated under vacuum, the average diameter of NF after heating in air is approximately $100 \mathrm{~nm}$ thinner. This may be the result of the oxidation of amorphous carbons and their release through vapor phase $\left(\mathrm{CO}_{2}\right)$. The removal of amorphous carbons from the NFs perhaps greatly reduced the sheet resistances. The above discussion can be explained by the following chemical reaction:

$$
\left[\mathrm{CH}_{2} \mathrm{CHOH}\right]_{n} \underset{\text { in vacuum }}{\stackrel{\mathrm{Pt}}{\longrightarrow}} \mathrm{C}+\mathrm{H}_{2}+\mathrm{H}_{2} \mathrm{O} \text {. }
$$

The preferred product of PVA thermal decomposition is $\mathrm{H}_{2} \mathrm{O}$, during heating under vacuum; hence, $\mathrm{C}$ cannot be oxidized by oxygen and residual amorphous carbons are produced. In contrast, as expressed in Eq. (1), air present during heating in air provides oxygen needed for the oxidation of carbons. Therefore, an open-air environment is more suitable for fabricating highly conductive Ag NFs.

In addition to providing a simple fabrication method, we considered whether the proposed method could be more efficient and energy-saving. Figure 4 displays the in-situ measurements of the sheet resistance. The specimen was pre-heated under vacuum (using a flow rate of $200 \mathrm{sccm}$ Ar gas and pressure of 130 $\mathrm{Pa}$, at $250^{\circ} \mathrm{C}$ for $30 \mathrm{~min}$ ) so that its initial sheet resistance was approximately $6340 \Omega / \square$. The specimen was then heated from $150^{\circ} \mathrm{C}$ to $250^{\circ} \mathrm{C}$ in air. The profile of the heating temperature is represented in Fig. 4 by the solid line, while the sheet resistance is represented by the dotted line. The sheet resistance increased almost linearly as the specimen was heated from $150{ }^{\circ} \mathrm{C}$ to $200^{\circ} \mathrm{C}$ because of the increase in the electrical resistivity as the temperature increased. Nevertheless, at $200^{\circ} \mathrm{C}$, the sheet resistance began to decrease rapidly, although the heating temperature continued to increase. After approximately $55 \mathrm{~min}$, the sheet resistance dropped from $6420 \Omega / \square$ to approximately $400 \Omega / \square$, and then the decreasing trend began to saturate. This might have been caused by the oxidation of amorphous carbons and their release, as discussed above. Therefore, the heating temperature can be reduced to approximately $200{ }^{\circ} \mathrm{C}$ for the fabrication of Ag NFs. This progress is not only helpful to save energy, but also widens the range of options for heat-resistant substrates. 


\section{Conclusions}

In summary, a simple method for fabricating Ag NFs via Pt nanoparticle-assisted reduction of $\mathrm{AgNO}_{3}$ was proposed, and the mechanism was investigated. Although the method needs to be improved further, it has high potential to produce high yields of Ag NFs with high aspect ratios and transparent conductive films in a simple, rapid, and economical manner. The Pt nanoparticles can be deposited onto a substrate by vacuum deposition or using commercial Pt dispersion liquid. In theory, most silver salts, such as silver chloride, silver sulfide, and silver fluoride, can be reduced; therefore, the source of $\mathrm{Ag}^{+}$is not limited to $\mathrm{AgNO}_{3}$. In addition, we predict that the other platinum group metals, such as $\mathrm{Pd}$ and $\mathrm{Rh}$, may produce the same catalytic effect as $\mathrm{Pt}$, because of their similar chemical properties.

\section{Abbreviations}

ITO: indium tin oxide

NW: nanowire

NF: nanofiber

$\mathrm{AgNO}_{3}:$ silver nitrate

PVA: polyvinyl alcohol

PVP: polyvinyl pyrrolidone

FE-SEM: field-emission scanning electron microscopy

HAADF-STEM: high-angle annular dark field scanning transmission electron microscopy

EDX: energy dispersive $\mathrm{X}$-ary

\section{Declarations}

Availability of data and materials: All data generated or analyzed during this study are included in this article.

Competing interests: The authors declare that they have no competing interests.

Funding: This study was partly supported by JSPS KAKENHI Grant Number 19 K04085.

Authors' contributions: X.Z. and M.M. contributed to the conception and experimental design. X.Z. and Y.K. contributes to the development of methodology and acquisition of data. X.Z. and M.M. contributed to the writing and revision of the manuscript. The authors have read and approved the final manuscript. 
Acknowledgment: This study was partly supported by JSPS KAKENHI Grant Number 19K04085.

\section{References}

1. Feng C, Liu K, Wu J, Liu L, Cheng J, Zhang Y, Sun Y, Li Q, Fan S, Jiang K. Flexible, stretchable, transparent conducting films made from superaligned carbon nanotubes. Adv Funct Mater 2010;20:885-91

2. Wu H, Hu L, Rowell MW, Kong D, Cha JJ, McDonough JR, Zhu J, Yang Y, McGehee MD, Cui Y. Electrospun metal nanofiber webs as high-performance transparent electrode. Nano Lett 2010;10:4242-8

3. Madaria AR, Kumar A, Zhou C. Large scale, highly conductive and patterned transparent films of silver nanowires on arbitrary substrates and their application in touch screens. Nanotechnology 2011;22:245201.

4. Tokuno T, Nogi M, Karakawa M, Jiu J, Nge TT, Aso Y, Suganuma K. Fabrication of silver nanowire transparent electrodes at room temperature. Nano Res 2011;4:1215-22

5. Wu H, Kong D, Ruan Z, Hsu PC, Wang S, Yu Z, Carney TJ, Hu L, Fan S, Cui Y. A transparent electrode based on a metal nanotrough network. Nat Nanotechnol 2013;8:421-5

6. Lin S, Bai X, Wang H, Wang H, Song J, Huang K, Wang C, Wang N, Li B, Lei M, Wu H. Roll-to-Roll production of transparent silver-nanofiber-network electrodes for flexible electrochromic smart windows. Adv Mater 2017;29:1703238.

7. Yoon YH, Song JW, Kim D, Kim J, Park JK, Oh SK, Han CS. Transparent film heater using singlewalled carbon nanotubes. Adv Mater 2007;19:4284-7

8. Kang J, Kim H, Kim KS, Lee SK, Bae S, Ahn JH, Kim YJ, Choi JB, Hong BH. High-performance graphene-based transparent flexible heaters. Nano Lett 2011;11:5154-8

9. Kim T, Kim YW, Lee HS, Kim H, Yang WS, Suh KS. Uniformly interconnected silver-nanowire networks for transparent film heaters. Adv Funct Mater 2013;23:1250-5

10. Rao KDM, Kulkarni GU. A highly crystalline single Au wire network as a high temperature transparent heater. Nanoscale 2014;6:5645-51

11. Hong S, Lee H, Lee J, Kwon J, Han S, Suh YD, Cho H, Shin J, Yeo J, Ko SH. Highly stretchable and transparent metal nanowire heater for wearable electronics applications. Adv Mater 2015;27:4744-51

12. Gelves GA, Al-Saleh MH, Sundararaj U. Highly electrically conductive and high performance EMI shielding nanowire/polymer nanocomposites by miscible mixing and precipitation. J Mater Chem 2011;21:829-36

13. Yang C, Gu H, Lin W, Yuen MM, Wong CP, Xiong M, Gao B. Silver nanowires: from scalable synthesis to recyclable foldable electronics. Adv Mater 2011;23:3052-6

14. Yu YH, Ma CCM, Teng CC, Huang YL, Lee SH, Wang I, Wei MH. Electrical, morphological, and electromagnetic interference shielding properties of silver nanowires and nanoparticles conductive composites. Mater Chem Phys 2012;136:334-40 
15. Granqvist CGHultåker A. Transparent and conducting ITO films: new developments and applications. Thin Solid Films 2002;411:1-5

16. Wu Z, Chen Z, Du X, Logan JM, Sippel J, Nikolou M, Kamaras K, Reynolds JR, Tanner DB, Hebard AF, Rinzler AG. Transparent, conductive carbon nanotube films. Science 2004;305:1273-6

17. Cai W, Zhu Y, Li X, Piner RD, Ruoff RS. Large area few-layer graphene/graphite films as transparent thin conducting electrodes. Appl Phys Lett 2009;95:123115.

18. Lee JH, Shin DW, Makotchenko VG, Nazarov AS, Fedorov VE, Kim YH, Choi JY, Kim JM, Yoo JB. Onestep exfoliation synthesis of easily soluble graphite and transparent conducting graphene sheets. Adv Mater 2009;21:4383-7

19. Xia Y, Sun K, Ouyang J. Solution-processed metallic conducting polymer films as transparent electrode of optoelectronic devices. Adv Mater 2012;24:2436-40

20. Lin H, Li L, Ren J, Cai Z, Qiu L, Yang Z, Peng H. Conducting polymer composite film incorporated with aligned carbon nanotubes for transparent, flexible and efficient supercapacitor. Sci Rep 2013;3:1353.

21. Sannicolo T, Lagrange M, Cabos A, Celle C, Simonato JP, Bellet D. Metallic nanowire-based transparent electrodes for next generation flexible devices: a review. Small 2016;12: (2016) 6052-75

22. Sun Y, Gates B, Mayers B, Xia Y. Crystalline silver nanowires by soft solution processing. Nano Lett 2002;2:165-8

23. Sun Y, Mayers B, Herricks T, Xia Y. Polyol synthesis of uniform silver nanowires: a plausible growth mechanism and the supporting evidence. Nano Lett 2003;3:955-60

24. Bergin SM, Chen YH, Rathmell AR, Charbonneau P, Li ZY, Wiley BJ. The effect of nanowire length and diameter on the properties of transparent, conducting nanowire films. Nanoscale 2012;4:1996-2004

25. Huang Y, Bai X, Zhou M, Liao S, Yu Z, Wang Y, Wu H. Large-scale spinning of silver nanofibers as flexible and reliable conductors. Nano Lett 2016;16:5846-51

26. Thornton JA, Hoffman DW. Stress-related effects in thin films. Thin Solid Films 1989;171:5-31

27. Koch R. The intrinsic stress of polycrystalline and epitaxial thin metal films. J Phys: Condens Matter 1994;6:9519.

28. Koch R. Stress in evaporated and sputtered thin films-a comparison. Surf Coat Technol 2010;204:1973-82

29. Chena W, Zhang J. Ag nanoparticles hosted in monolithic mesoporous silica by thermal decomposition method. Scr Mater 2003;49:321-5

30. Ballistreri A, Foti S, Montaudo G, Scamporrino E. Evolution of aromatic compounds in the thermal decomposition of vinyl polymers. J Polym Sci, Part A: Polym Chem 1980;18:1147-53

31. Lomakin SM, Artsis MI, Zaikov GE. Thermal and oxydative stability of PVA and nylon 6, 6. Int J Polym Mater 1994;26:187-94

32. Holland BJ, Hay JN. The thermal degradation of poly (vinyl alcohol). Polymer 2001;42:6775-83

33. Prosanov IY, Matvienko AA. Study of PVA thermal destruction by means of IR and Raman spectroscopy. Phys Solid State 2010;52:2203-6 
Figures

(a) Sputtering

(b) $-\mathrm{PVA}+\mathrm{PVP}+\mathrm{AgNO}_{3}$ (c) Ag nanofibers

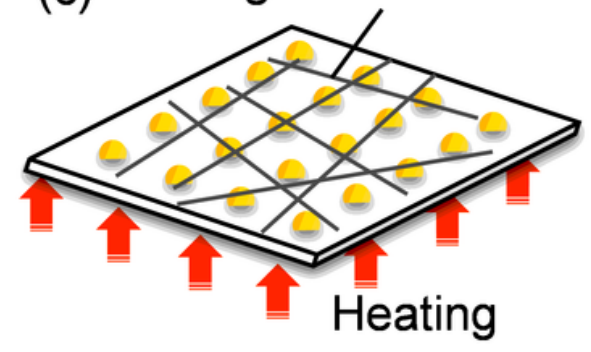

Figure 1

Schematic showing the Ag NF networks fabrication process: (a) Pt sputtering, (b) electrospinning of AgN03/PVA/PVP-mixed NF network, and (c) heating in air.
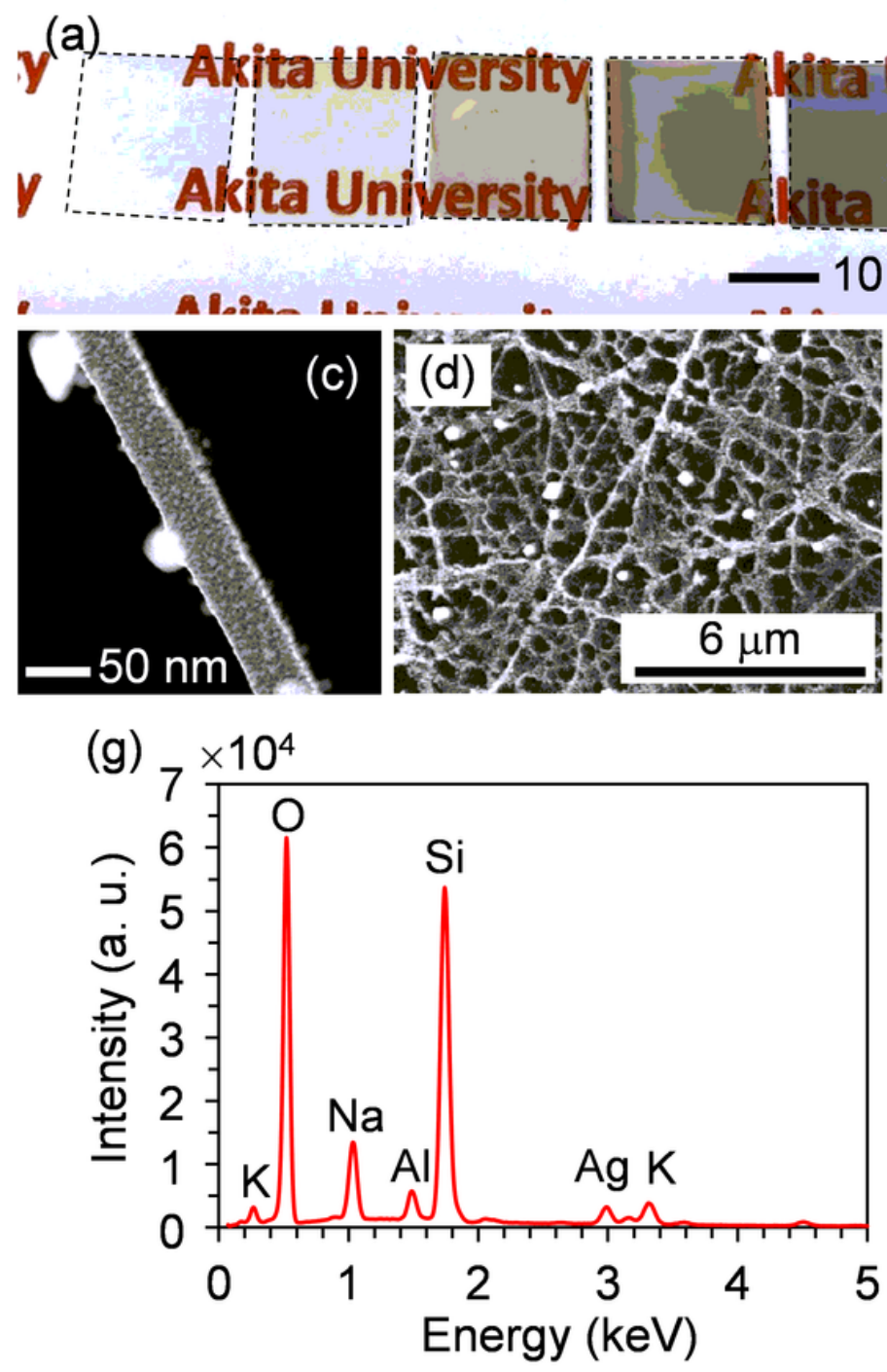

(b)

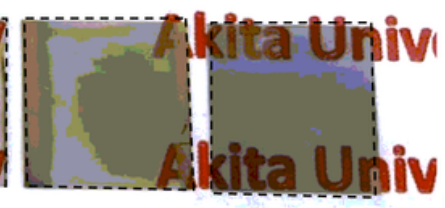
$10 \mathrm{~mm}$
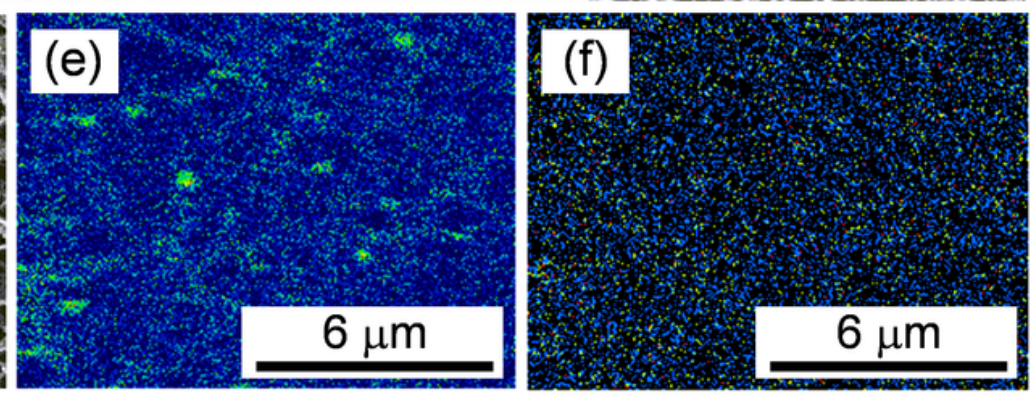

(h) 5

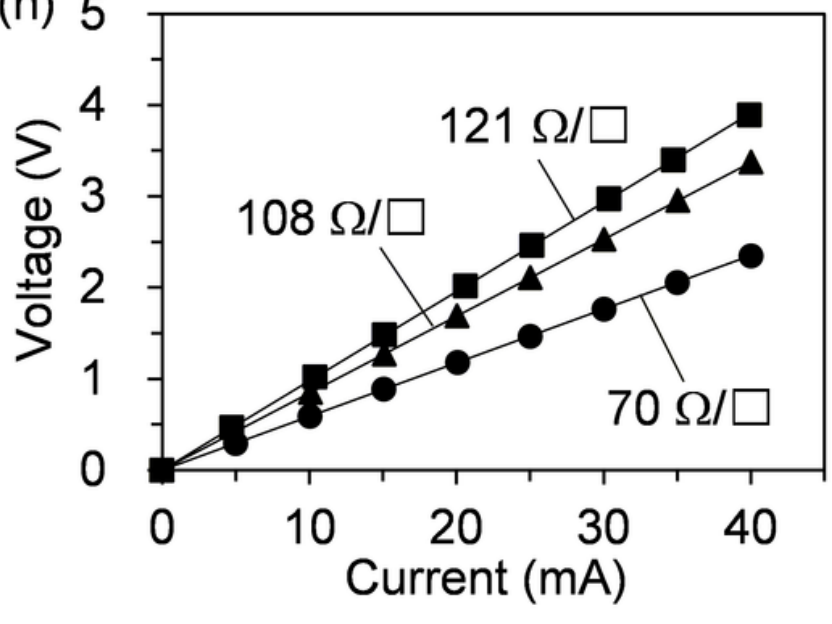

Figure 2 
(a) States of the specimens during the experiment. (b) Optical and FE-SEM images of the specimen after heating. (c) HAADF-STEM image of an Ag NF. EDX analysis results of the Ag NF network: (d) SEM image, (e) Ag, and (f) C distribution mappings, and (g) qualitative analysis of the area shown in (d). (h) Currentvoltage curves of the specimens measured using the four-probe method.
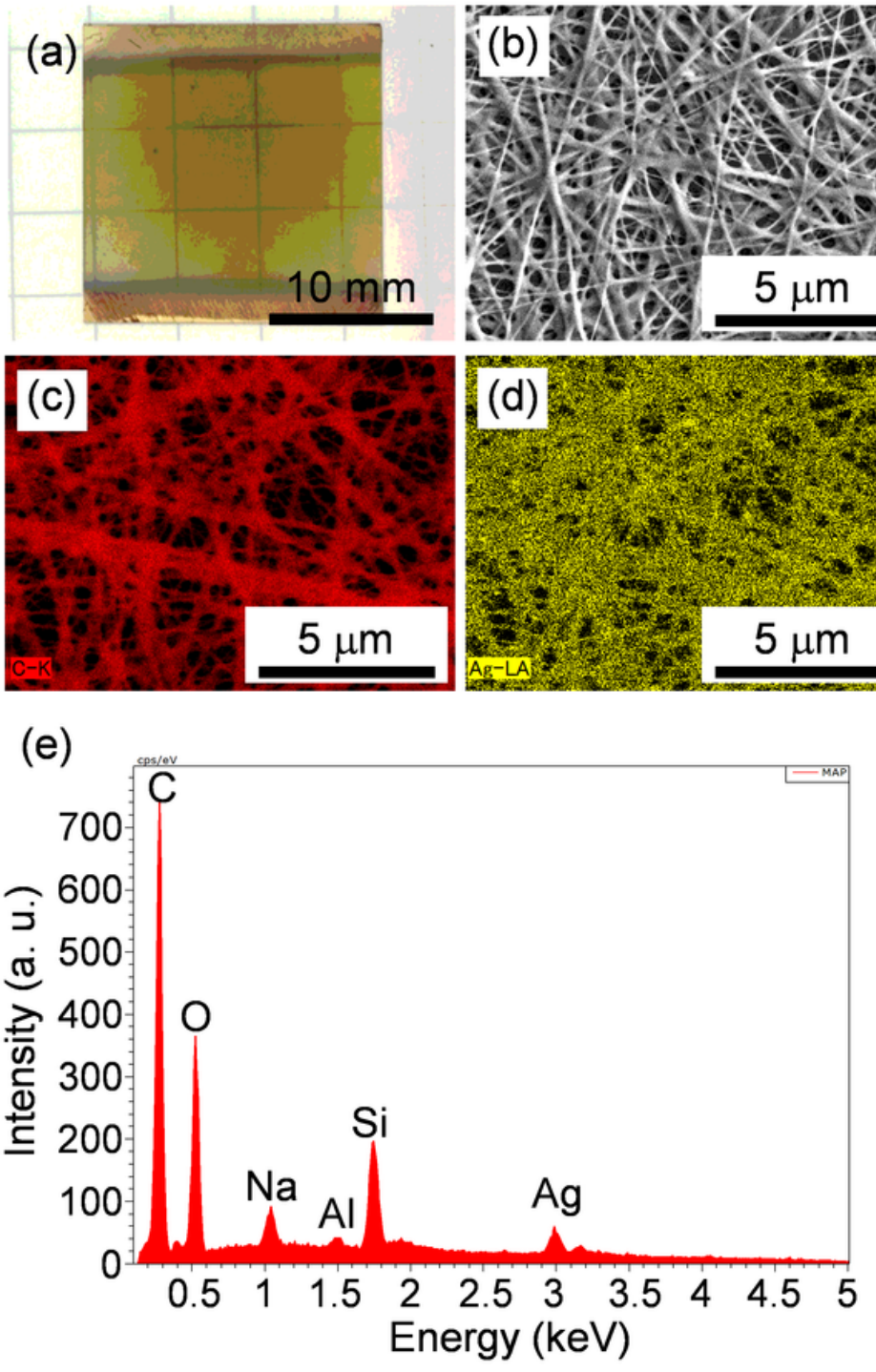
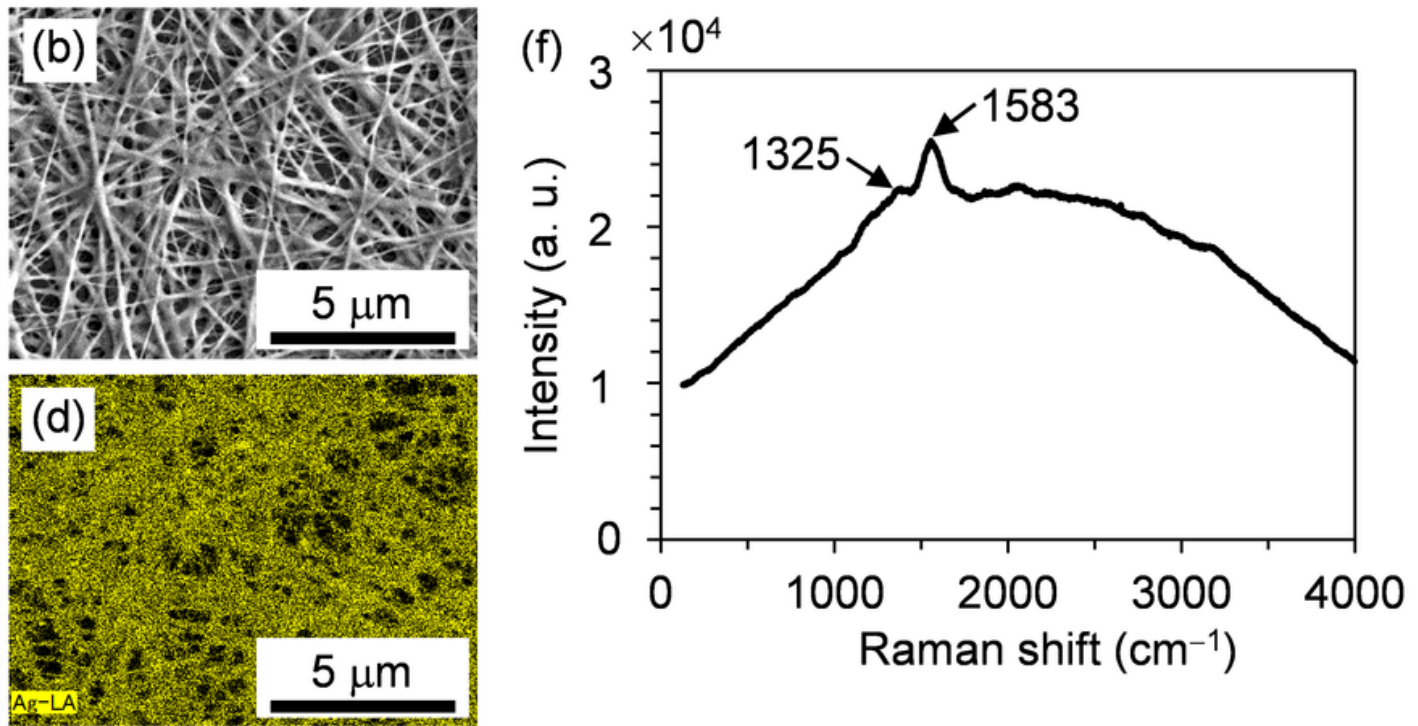

(g)

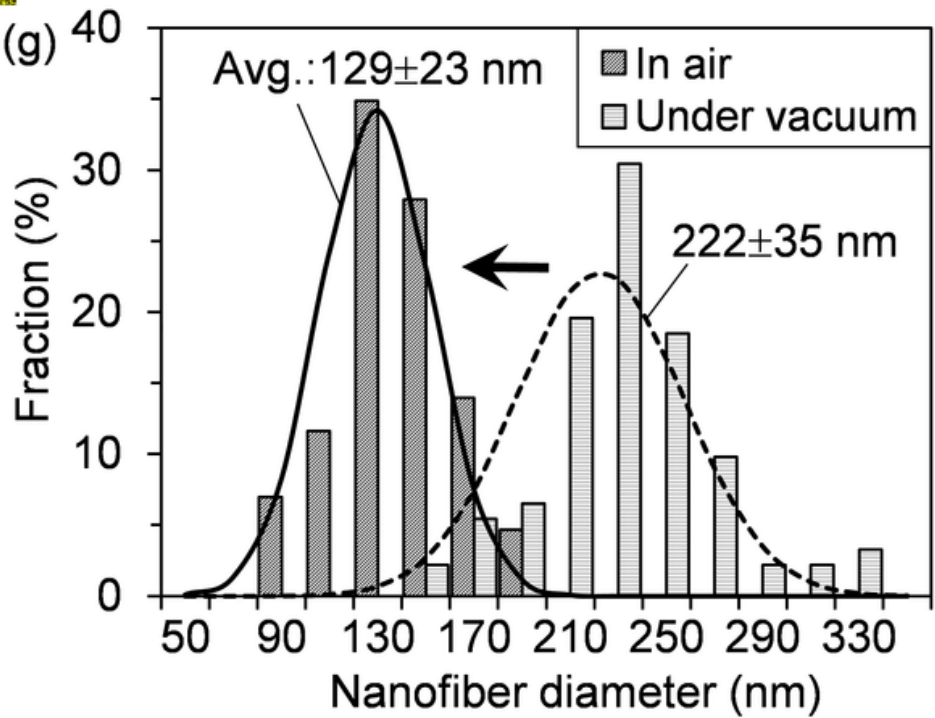

\section{Figure 3}

Specimen after heating under vacuum with (a) optical image, EDX analysis results: (b) SEM, (c) C, and (d) Ag distribution mappings; (e) qualitative analysis of the area shown in (b); and ( $f$ ) the Raman spectrum. (g) Histograms of the NF diameter after heating in air and under vacuum. 


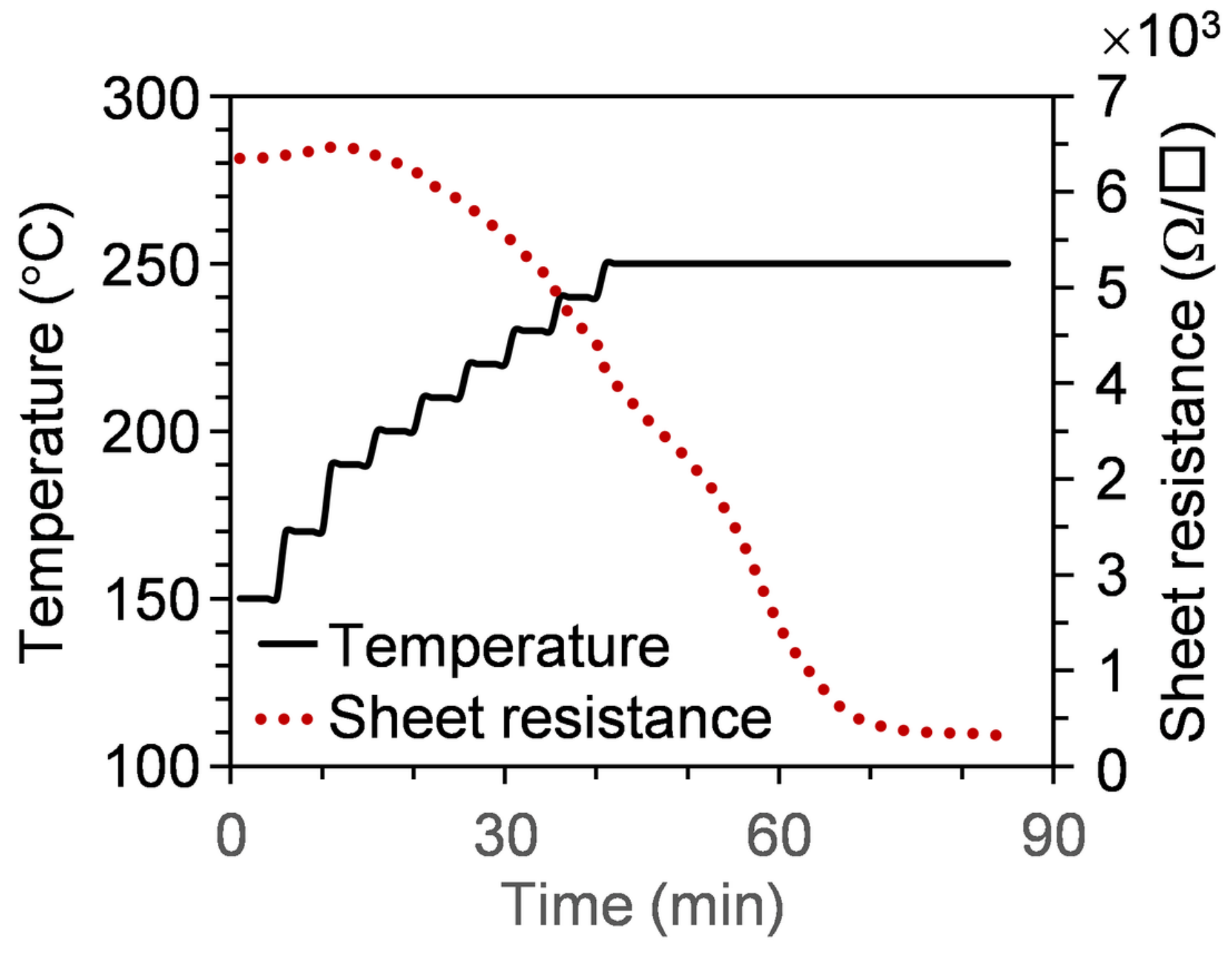

Figure 4

Variation in the sheet resistance with heating temperature and time. 